\title{
A Rare and Unusual Complication of Kyphoplasty: A Case Report of Spinal Subdural Hemotoma
}

\author{
Necati Kaplan ${ }^{1}$ (D), Yener Akyuva² (D), Göksel Güven ${ }^{1}$ \\ ${ }^{1}$ Department of Neurosurgery, İstanbul Rumeli University School of Medicine, İstanbul, Turkey \\ 2Department of Neurosurgery, University of Health Sciences Gaziosmanpaşa Taksim Traning and Research Hospital, İstanbul, Turkey
}

Cite this article as: Kaplan N, Akyuva Y, Güven G. A Rare and Unusual Complication of Kyphoplasty: A Case Report of Spinal Subdural Hemotoma. JAREM 2019; 9(2): 107-10.

\begin{abstract}
For vertebral fractures, kyphoplasty appears to be the most innocent treatment modality, but percutaneous injection of kyphoplasty cement might cause serious complications as the injection causes increased venous pressure in paravertebralspace. Here, we report a case of late-onset spinal subdural hemotoma after $6 \mathrm{~h}$ of percutaneous balloon kyphoplasty. A 58-year-old female with an acute compression fracture of the second lumbar vertebrae underwent percutaneous balloon kyphoplasty. After $6 \mathrm{~h}$, she had late-onset neurological deficits and leg pain. Emergent lumbar MR was performed. The MR images revealed intraspinal hemotoma. The patient was operated, and spinal subdural hemotoma was removed. Spinal subdural or epidural hemotoma is believed to occur because of increased venous drainage pressure that leads to the rupture of venous vessels following kyphoplasty. These hematomas should be immediately removed, otherwise irreversible neurological complications may occur.
\end{abstract}

Keywords: Polymethyl methacrylate cement, subdural hemotoma, kyphoplasty, intraspinal hemotoma

\section{INTRODUCTION}

Kyphoplasty is a minimally invasive surgical procedure to treat vertebral body compression fractures. The complication rate of this procedure is low, i.e., 1\%-2\% for osteoporotic fractures and $5 \%-10 \%$ for metastatic lesions $(1,2)$. The most common complication of kyphoplasty is temporary increase in pain following the procedure. Development of acute radiculopathy was reported in $5 \%$ of cases. Cement leakage is a common complication, especially in lytic lesions, and it was reported in 30\%-70\% of cases (3). Other well-known complications include fractures of the ribs or pedicle, pneumothorax, spinal cord compromise, and infection. More severe complications, such as pulmonary embolism and death during or immediately after vertebroplasty or kyphoplasty have also been reported in the literature (3-5).

The causes for these complications remain unelucidated; however, they are thought to be related to the insufficient polymerization of the Polymethyl methacrylate PMMA during injection or the number of fractured vertebral bodies treated. In this study, we report a case of late-onset intraduralhemotoma following single-level kyphoplasty.

\section{CASE PRESENTATION}

A 58-year-old female presented to our neurosurgery outpatient clinic with severe lower back pain. She stated the she fell on her back three days ago. Her past medical history was unremarkable,and at the time, she was not taking any medications. She was neurologically intact during physical examination, and her initial evaluation routine lumbar X-ray studies revealed an L2 compression fracture. Images of magnetic resonance imaging (MRI) using short tau inversion recovery (STIR) sequences of the patient revealed an acute compression fracture of L2 with $40 \%$ loss of vertebral body height and a slight angulation toward the spinal canal at its superior endplate (Figure 1. a, b). She was admitted to our clinic for balloon kyphoplasty. After routine preparations, she underwent a bipedicular L2 vertebral kyphoplasty (Figure 1. c, d). Following kyphoplasty, her pain had completely resolved, and she had no neurological deficit. To prevent postoperative development of pulmonary embolism, she was prophylactically administered 6000 units of low molecular weight heparin.

The patient was mobilized 6h post-operation. During mobilization, she reported pain in her legs. She had no neu- 


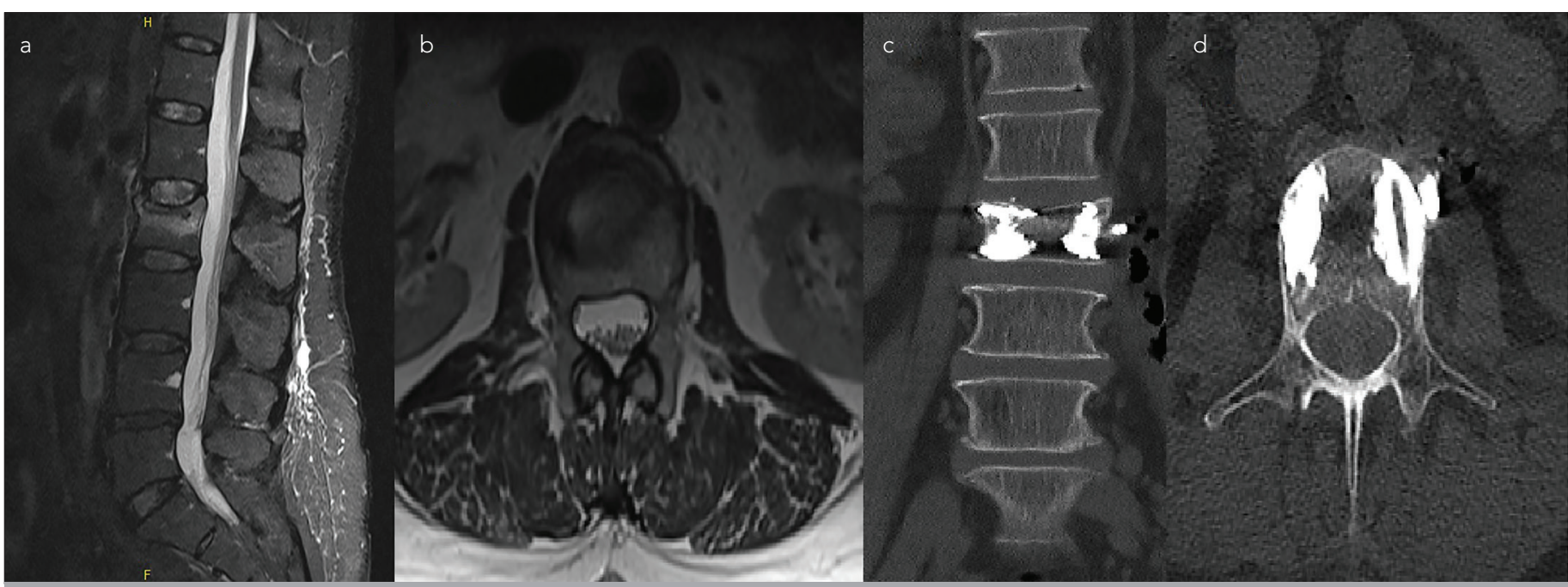

Figure 1. a-d. Preoperative sagittal lumber STIR MR images revealed L2 acute vertebra fracture (a) Preoperative axial lumber T2 MR images revealed no pathology at the level of fracture (b) Postoperative coronal CT images revealed no pathology (c) Postoperative axial CT images revealed a normal route of the Jamshidi needle (d)

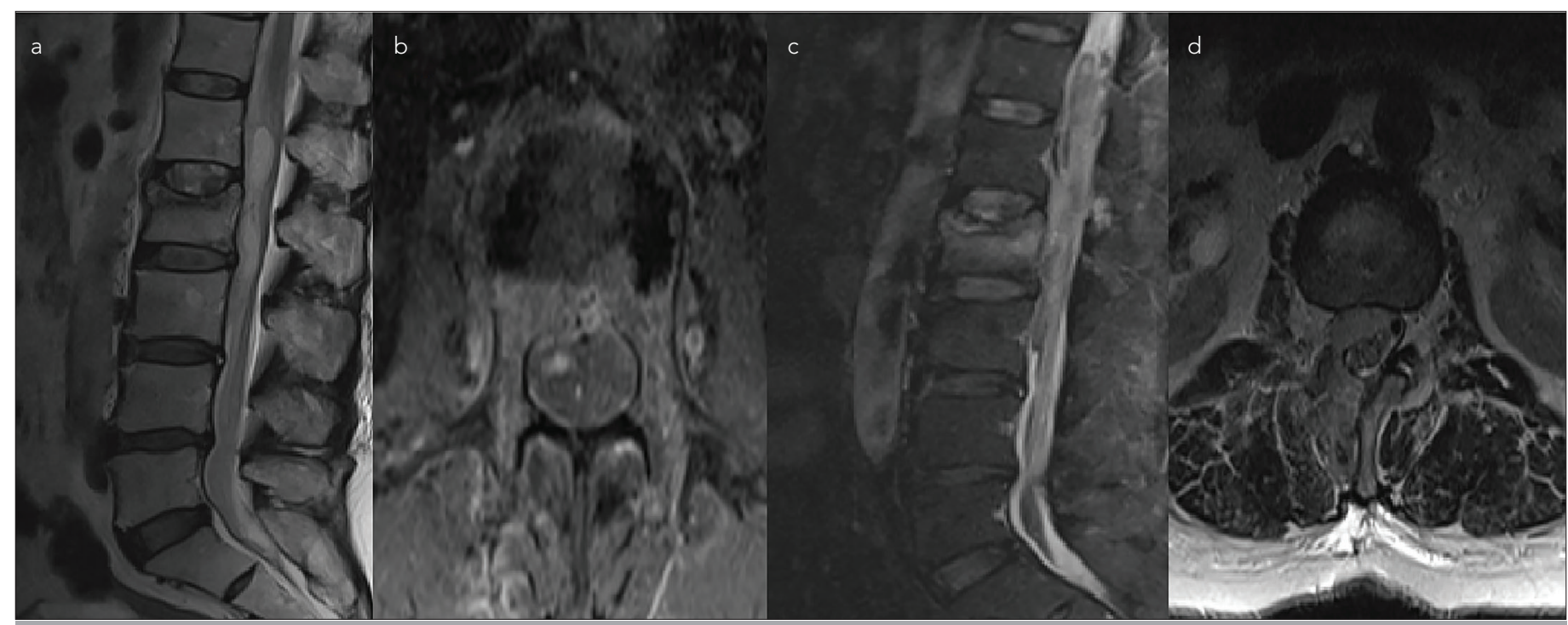

Figure 2. a-d. Postoperative T2 sagittal MR images revealed intraspinal hemotoma (a)Postoperative contrast-enhancedaxial MR images revealed subdural hemotoma (b)After second operation, T2 sagittal MR images revealed epidural hemotoma (c)After second operation, T2 axial MR images revealed epidural hemotoma (d)

rological deficit at that time. For control purposes, she was sent for lumber computed tomography (CT) imaging. No pathological findings were detected on CT. She was then evaluated using lumbar MRI to find the cause of pain. MRI images revealed a consistent collection of acute intradural hematoma inside the dural sac approximately $8 \mathrm{~cm}$ long between the L1-L3 vertebral bodies, which caused a significant compression of the dural sac fibers (Figure 2. $a, b)$. She was immediately taken to the operation room for decompression of the spinal canal. During surgery, the epidural area was observed clean without any hemotoma or cerebrospinal fluid (CSF) leakage. Dura mater was also intact; however, purple-colored collection could be clearly observed inside the sac. Durotomy using a wide decompressive laminectomy was performed. Intradural hematoma was easily visible and was successfully removed thereafter. Dural opening was closed with duraplasty. Hemostasis for a significant bleeding from an epidural vessel was achieved by applying fibrin glue and the operation was concluded.

There was no significant neurological deficit during early postoperative examination. After $24 \mathrm{~h}$, the patient had right leg pain with paraparesis. Assessment of MRI images revealed an epidural hemotoma having dimensions 20.4 $\mathrm{mm}, 21.6 \mathrm{~mm}$, and $19.9 \mathrm{~mm}$ in the L1-L2-L3 levels (Figure 2. c, d). Therefore, we drained the epidural hemotoma caused by an epidural vessel. It was observed that the neuromotor deficit of the patient was better, which gradually decreased after the final operation. With rehabilita- 
tion program, on the postoperative eighth day, she began to walk independently, and was subsequently discharged to the outpatient clinic control.

\section{DISCUSSION}

Osteoporosis has been defined as a systemic syndrome involving primarily the skeleton, characterized by low bone mass and micro-architectural degeneration of bone tissue, which leads to bone fragility and increased fracture risk (6). The major clinical manifestation of osteoporosis is fracture (7). Most osteoporotic vertebral fractures are conservatively treated with a bed rest period, pain control with analgesics, bracing, early rehabilitation, and treatment with bisphosphonates (8).

Percutaneous kyphoplasty is a therapeutic strategy that gained increasing popularity among the neurosurgical community for the treatment of refractory axial mechanical pain due to osteoporotic fractures, malignancy fractures, and painful hemangiomas (5). With time, the indications for kyphoplasty were extended to include acute traumatic vertebral compression fractures (9).

The complications reported in the literature are often related to the cement extravasation into the epidural space (10) causing spinal cord compression or related to the cement migration through the epidural veins to the venous system leading to pulmonary embolism (11). To our knowledge, till date, only 6 cases of subdural hematoma (SDH), including our case, have been reported in the literature $(5,10-12)$. This complication was rare. Written consent was obtained from the patient for the publication of this study.

Tropeano et al. (5), Cosar et al. (12), Mattei et al. (13), and Lee et al. (12) reported on patients who developed spinal SDH after kyphoplasty. Time for symptoms to appear differed from immediately after to two weeks later. In all cases, patients were operated when neurological deficit occurred except for the case reported by Lee et al (12). Lee at al did not require a surgical treatment because the patient did not have a neurological deficit. All patients recovered without neurological deficits.

When we reviewed the literature, we found that the cases of SDH developed following vertebroplasty/kyphoplasty were usually caused by slow infiltration of epidural hemotoma into subdural space after dural injury during operation (12). Some authors also suggested that the source of these subdural hemotoma could be extra arachnoid vessels that have been identified on the inner dural surface. These vessels possibly ruptured because of elevated pressure due to venous congestion caused by cement thrombosis of vertebral venous plexus (13). In our case, we were sure that we had no dural injury during the operation, and the track of the Jamshidi needle could be easily seen in the pedicle area with no crossing over sign in postoperative CT and MRI images. Moreover, we did not find any collection of CSF or dural tear during operation for the evacuation of subdural hemotoma.

\section{CONCLUSION}

Our case is a very rare postoperative complication of kyphoplasty. Subdural or epidural hemotoma is believed to occur because of increased venous drainage pressure that leads to the rupture of venous vessels. These hematomas should be immediately removed, otherwise irreversible neurological complications may occur.

Informed Consent: Written informed consent was obtained from patient who participated in this study.

Peer-review: Externally peer-reviewed.

Author Contributions: Concept - N.K.; Design - Y.A.; Supervision - G.G.; Resources - G.G.; Materials - N.K.; Data Collection and/or Processing N.K.; Analysis and/or Interpretation - Y.A.; Literature Search - Y.A.; Writing Manuscript - N.K.; Critical Review - G.G.; Other - Y.A.

Conflict of Interest: The authors have no conflict of interest to declare.

Financial Disclosure: The authors declared that this study has received no financial support.

\section{REFERENCES}

1. Phillips FM. Minimally invasive treatments of osteoporotic vertebral compression fractures. Spine 2003; 28: 45-53. [CrossRef]

2. Bernadette Stallemeyer MJ, Zoarski GH, Obuchowski AM. Optimising patient selection in percutaneous vertebroplasty. J Vasc Intervent Radiol 2003; 14: 683-96. [CrossRef]

3. Conesa X, Seijas R, Ares O, Huguet P, Perez-Dominguez M. Multicentric liposarcoma. Acta Orthop Belg 2011; 77: 9-14.

4. Schwab JH, Boland P, Guo T, Brennan MF, Singer S, Healey JH, et al. Skeletal metastases in myxoid liposarcoma: an unusual pattern of distant spread. Ann Surg Oncol 2007; 14: 1507-14. [CrossRef]

5. Tropeano MP, La Pira B, Pescatori L, Piccirilli M. Vertebroplasty and delayed subdural cauda equina hematoma: Review of literature and case report. World J Clin Cases 2017; 5: 333-9. [CrossRef]

6. Christiansen C. Consensus development conference: prophylaxis and treatment of osteoporosis. Am J Med 1991; 90: 107-10. [CrossRef]

7. Stitik TP. Spine Surgery: Techniques, Complication Avoidance, and Management. 2001: 424.

8. Longo UG, Loppini M, Denaro L, Maffulli N, Denaro V. Osteoporotic vertebral fractures: current concepts of conservative care. $\mathrm{Br}$ Med Bull 2012; 102: 171-89. [CrossRef]

9. Lieberman I, Reinhardt MK. Vertebroplasty and kyphoplasty for osteolytic vertebral collapse. Clin Orthop Relat Res 2003; 415: 176-86. [CrossRef]

10. Zheng ZM. The disaster complication of percutaneous vertebroplasty and kyphoplasty: cement leakage and its prevention. Zhonghua Yi Xue Za Zhi 2006; 86: 3027-30.

11. Baumann A, Tauss J, Baumann G, Tomka M, Hessinger M, Tiesenhausen $\mathrm{K}$. Cement embolization into the vena cava and pulmonal 
arteries after vertebroplasty: interdisciplinary management. Eur J Vasc Endovasc Surg 2006; 31: 558-61. [CrossRef]

12. Cosar M, Sasani M, Oktenoglu T, Kaner T, Ercelen O, Kose KC, et al. The major complications of transpedicular vertebroplasty. $J$ Neurosurg Spine 2009; 11: 607-13. [CrossRef]
13. Mattei TA, Rehman AA, Dinh DH. Acute spinal subdural hematoma after vertebroplasty: A case report emphasizing the possible etiologic role of venous congestion. Global Spine J 2015; 5: 52-8.

\section{[CrossRef]}

